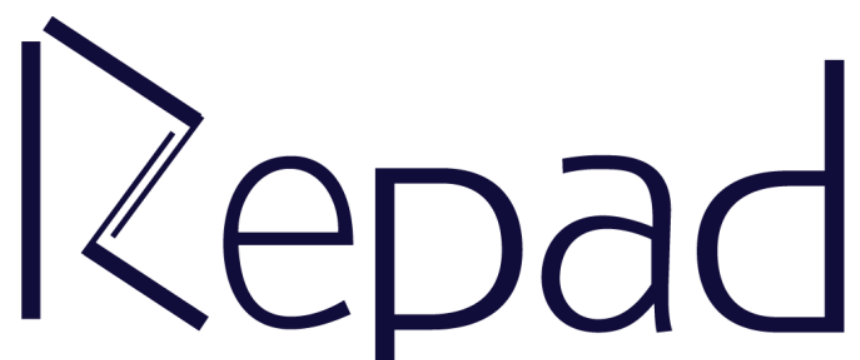

Vol. 2, n 2, AGOSTO/2018

Revista Estudos e

Pesquisas em Administração

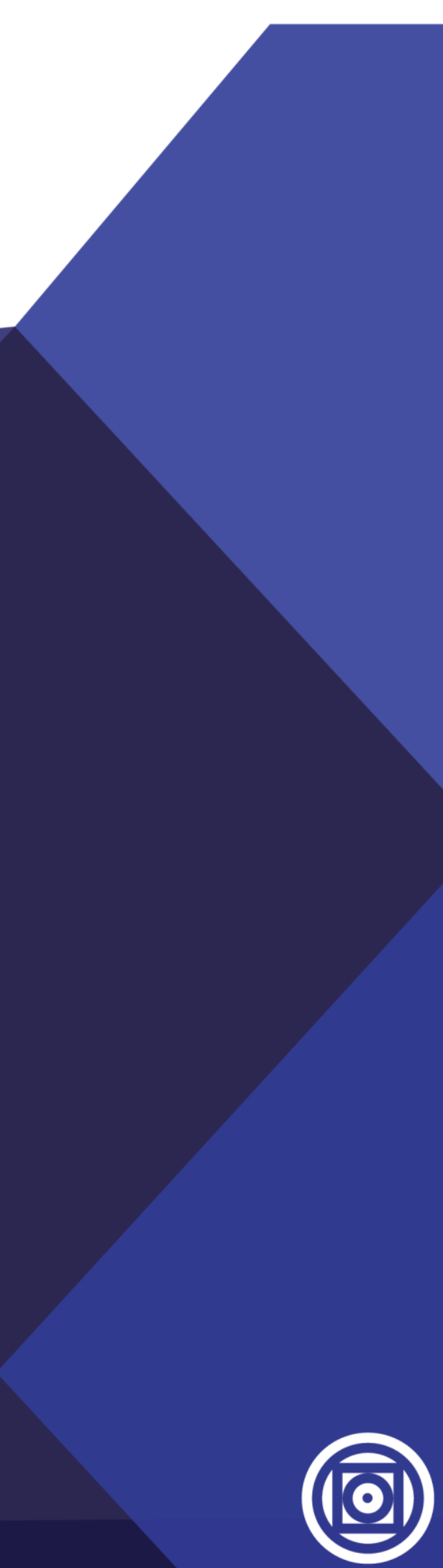




\title{
EM BUSCA DA ESCOLA IDEAL: Os motivos que pesam na hora da melhor escolha
}

\section{IN SEARCH OF THE IDEAL SCHOOL: The reasons to be taken into account for a better choice}

\begin{abstract}
Mirella Vicente de Carvalho Faculdade de Administração e Ciências Contábeis da Universidade Federal de Mato Grosso https://orcid.org/0000-0002-1173-6043
\end{abstract}

Diogo Barbosa Leite Instituto Federal de Educação, Ciência e Tecnologia de Mato Grosso - Primavera do Leste https://orcid.org/0000-0002-8490-0502

Silvana Santos da Cruz Pró-reitoria de Pesquisa e Inovação do Instituto Federal de Educação, Ciência e Tecnologia de Mato Grosso https://orcid.org/0000-0001-5872-8916

\section{RESUMO}

Foi realizada uma investigação numa determinada escola para avaliar quais são os fatores de influência na escolha da instituição de ensino. O objetivo fundamental é pesquisar o comportamento de compra e o processo de escolha dos clientes da instituição analisada. A pesquisa foi dividida em duas partes: a primeira caracteriza-se como estudo de caso, com objetivo explicativo, abordagem qualitativa e utilizando, como instrumento de coleta de dados, um roteiro semiestruturado, que foi aplicado à gestora da escola; a segunda fase se configura como um levantamento, com objetivo descritivo e abordagem quantitativa realizada por meio de um questionário estruturado aplicado aos pais dos alunos. O corte do estudo é transversal e os dados foram coletados no mês de fevereiro de 2017. Os principais resultados se relacionam quanto às peculiaridades do segmento, sendo os grupos de referência os maiores influenciadores destes consumidores. Constatou-se que, mais do que pela comunicação, estes consumidores se pautam por indicações de pessoas as quais reportam credibilidade. Ademais, verificou-se que estes pais, diferente do que a própria gestora afirmou, não buscam status quando procuram a escola de seus filhos, mas instituições que zelam pela metodologia educacional.

Palavras-chave: Processo de escolha; Fatores de escolha; Comportamento de compra; Satisfação; Instituição de Ensino.

\begin{abstract}
In search of a basis for what parents value during the search of a school and / or nursery for their children, an assessment was carried out in a certain school to evaluate what the influence factors of the educational institution are. The fundamental objective is to investigate the process of choosing and the purchase behavior of the clients of the analyzed school. The research was divided in two parts: the first is characterized as an explanatory-purposed case study, using a qualitative approach and a semi-structured script applied to the school manager as a data collection instrument; The second phase is configured as a survey, with a descriptive objective, and a quantitative approach based on a structured questionnaire applied to the students' parents.
\end{abstract}


The study was cross-sectional and data were collected in February 2017. The main results are related to the peculiarities of the segment, being the groups of reference extremely important to these consumers. It has been found that more than through communication, these consumers are guided by indications from people for whom they report credibility. It was also found that these parents, different from what the manager herself said, do not seek Social status when they seek their children's school, but institutions that care for educational methodology.

Keywords: Process of choice; Factors of choice; Buying behavior; Satisfaction. Educational Institution.

\section{INTRODUÇÃO}

O modelo familiar variou de acordo com a composição histórica, social e econômica ao longo dos anos e, por sua vez, acompanhou o momento histórico, os acontecimentos políticos e os interesses por eles despertados. No século XX, um conjunto de circunstâncias especialmente relacionadas ao processo de urbanização e desenvolvimento das cidades e à entrada das mulheres no mercado de trabalho levou a mudanças econômicas da sociedade (SIMÕES, 2012). Nessa entrada das mulheres na vida profissional, de acordo com pesquisa realizada em 2008 pelo IBGE (Instituto Brasileiro de Geografia e Estatística), aproximadamente $43,1 \%$ das mulheres se encontram no mercado de trabalho com uma jornada média de 40 horas semanais. Isso transformou a forma de criar e educar os filhos e fez com que o número de locais dedicados à educação de crianças de zero a três anos crescesse consideravelmente: em consulta ao Censo Escolar da Educação Básica, do Instituto Nacional de Estudos e Pesquisas Educacionais Anísio Teixeira, o INEP, observou-se que, no ano de 2014, o número de escolas privadas de educação infantil em todo o país era de 31.638.

Colocar a criança na escola deixou de ser uma possibilidade para se tornar, então, uma necessidade. Juntando isso ao fato de que os pais brasileiros estão entre os que mais se preocupam com a educação dos filhos (de acordo com o relatório "O valor da educação", do Hong Kong and Shanghai Banking Corporation - HSBC, de 2014, que pesquisa sobre o consumidor independente e as tendências globais de educação), ajuda a explicar a profusão de informação e conteúdo sobre o tema nas últimas décadas.

Segundo os estudos de Héran (1996, apud Nogueira, 1998), os critérios de escolha da instituição de ensino apresentados pelas famílias - e a complexa variação dos mesmos - são eleitos com base em valores subjetivos e aspectos objetivos, de ordem prática. Ou seja, além dos atributos físicos da escola, como localização, estrutura física, método de ensino, valor da mensalidade, entre outros, essa escolha leva em consideração aspectos como valores religiosos e culturais dos pais; as expectativas e aspirações da família sobre a escolarização do filho; o status pretendido; a identificação e adequação das características pessoais e de potencial escolar do filho com a instituição de ensino.

Inserido neste contexto, entende-se que muitos atributos podem se sobressair aos demais na escolha de uma escola. Portanto, este estudo de caso tem como questão problema "quais são os fatores de influência que levam à escolha de uma instituição de ensino para educação de crianças?".

Como decorrência, a investigação tem por objetivo geral pesquisar o comportamento de compra e o processo de escolha dos clientes da escola analisada. Para isso, deve elencar os principais fatores críticos de sucesso da escola a partir da sua perspectiva de atuação e identificar os fatores do processo de escolha, como nos aspectos que mantém os clientes. 
Economicamente, esta investigação se faz pertinente já que, de acordo com estudo da Federação Nacional das Escolas Particulares (FENEP) em parceria com a Fundação Getúlio Vargas (2013), o número de matrículas na rede privada de educação básica, no período, teve uma taxa de crescimento acumulada de $11,99 \%$, o que equivale a um acréscimo anual médio de 1,63\%. Outro estudo (2006) de pesquisadores do Instituto de Pesquisa Econômica Aplicada (IPEA) mostra que, por gerarem muitos empregos num determinado estrato social, os investimentos em educação dão grande incremento à economia e à renda das famílias. Além disso, a relevância acadêmica deste artigo se dá pelo seu ineditismo, já que se trata do comportamento do consumidor quanto à área da educação infantil, ainda considerado pouco consolidado.

\section{O QUE INFLUENCIA O COMPORTAMENTO DO CONSUMIDOR?}

Segundo a definição da American Marketing Association (AMA), em tradução livre, "Marketing é a atividade, conjunto de instituições e processos para criar, comunicar, entregar e trocar ofertas que tenham valor para consumidores, clientes, parceiros e sociedade em geral". A administração de marketing é a arte e a ciência de escolher mercados-alvo e obter, manter e multiplicar clientes por meio da criação, da entrega e da comunicação de um valor superior para o cliente (KOTLER, KELLER, 2006).

Las Casas (2012) afirma que o marketing engloba todas as atividades concernentes às relações de troca, orientadas para a satisfação dos desejos e necessidades dos consumidores visando alcançar determinados objetivos de empresas ou indivíduos e considerando sempre o ambiente de atuação e o impacto que essas relações causam no bem-estar da sociedade.

Para possibilitar que os profissionais do marketing sejam bem-sucedidos e alcancem a satisfação dos clientes, é necessário o estudo do comportamento do consumidor, que permite conhecer o que querem e desejam os consumidores, e ainda o modo como estes tomam suas decisões de compra e utilizam os produtos e serviços (SHETH, MITTAL, NEWMAN, 2001).

Conforme a American Marketing Association (AMA), o comportamento do consumidor é a "interação dinâmica entre afeto e cognição, comportamento e ambiente por meio da qual os seres humanos conduzem na vida atitudes relacionadas à troca". Em outras palavras, Peter e Olson (2009) afirmam que o comportamento do consumidor envolve os pensamentos e os sentimentos que as pessoas experimentam e suas respectivas ações no processo de consumo isso inclui todo o universo que cerca e influencia este ambiente de escolha, como o próprio ambiente, opiniões alheias, propagandas, entre outros.

Segundo Solomon (2016), o comportamento do consumidor é o estudo dos processos envolvidos quando indivíduos ou grupos selecionam, compram, usam ou descartam produtos, serviços, ideias ou experiências para satisfazerem necessidades e desejos.

Convergindo para o mesmo pensamento, Kotler (2000) afirma que, o ponto de partida para se compreender o comportamento do consumidor é o modelo de estímulo e resposta, exemplificado no quadro a seguir, onde as características do comprador e seus processos de decisão o levam a determinadas decisões de compra. 
Figura 1. Modelo de estímulo e resposta

\begin{tabular}{ll}
\hline $\begin{array}{c}\text { Estímulos } \\
\text { de } \\
\text { Marketing }\end{array}$ & \multicolumn{1}{c}{$\begin{array}{c}\text { Outros } \\
\text { estímulos }\end{array}$} \\
\hline Produto & Econômico \\
Preço & Tecnológico \\
Praça & Político \\
Promoção & Cultural \\
& \\
\hline
\end{tabular}

\begin{tabular}{lccc}
\hline $\begin{array}{l}\text { Características } \\
\text { do comprador }\end{array}$ & $\begin{array}{c}\text { Processo de decisão do } \\
\text { comprador }\end{array}$ & & Decisões do comprador \\
\cline { 1 - 1 } Culturais & Reconhecimento de problemas & & Escolha do produto \\
Sociais & Busca de informações & & Escolha da marca \\
Pessoais & Avaliação de alternativas & & Escolha do revendedor \\
Psicológicas & Decisão de compra & & Frequência de compra \\
& Comportamento após a compra & & Montante de compra \\
& & & \\
\hline
\end{tabular}

Fonte: $\operatorname{Kotler}(2000$, p. 183)

Ainda de acordo com Solomon (2016), o consumidor é considerado como a pessoa que identifica uma necessidade ou desejo, realiza uma compra e depois descarta o produto ao longo de três estágios do processo de consumo - pré-compra, compra e pós-compra.

O ato de compra, segundo Karsaklian (2000), não surge do nada. Seu ponto de partida é a motivação ou o reconhecimento do problema, que vai conduzir a uma necessidade, a qual, por sua vez, despertará um desejo. Com base em tal desejo, surgem as preferências por determinadas formas específicas de atender à motivação inicial e essas preferências estarão diretamente relacionadas ao autoconceito: o consumidor tenderá a escolher um produto que corresponda ao conceito que ele tem ou que gostaria de ter de si mesmo. No entanto, e em sentido contrário à motivação, surgem os freios. Estes são a consciência de risco que vem implícita ou explicitamente relacionada com o produto.

Em meio ao dilema entre a força da motivação e aos freios, impõe-se a personalidade do indivíduo, a qual resultará no autoconceito. A reunião de todas essas variáveis resulta em uma percepção particular dos produtos, que, por sua vez, desencadeará atitudes positivas ou negativas com relação a eles, o que, naturalmente, terá impacto sobre suas preferências (KARSAKLIAN, 2000).

Os fatores culturais são determinantes no comportamento do consumidor, haja vista que uma pessoa nasce e cresce em determinada cultura, afunilada a uma subcultura (com características distintas de comportamentos de uma cultura mais ampla), e em uma determinada estratificação social - essa não reflete apenas a renda da família daquela criança, mas pode representar um indicativo, também, do grau de instrução e de sua área de residência. As classes sociais apresentam preferências nítidas por produtos e marcas, em diversas áreas (KOTLER, 2000).

Já os fatores tratados como sociais, como os grupos de referência, família, papéis sociais e status, segundo Kotler (2000), induzem diretamente o consumidor. Os grupos de referência são formados por pessoas que sugestionam significativamente o consumidor (direta ou indiretamente) já que o expõem a novos comportamentos e estilo de vida, influenciam as atitudes e a autoimagem e fazem pressão em relação à conformidade que podem afetar as escolhas reais de produto e marca. De acordo com Solomon (2016), esses grupos podem ter três tipos de influência: informacional (o indivíduo procura informações, por exemplo, entre pessoas que lidam profissionalmente com o produto); utilitária (a decisão do indivíduo de comprar uma determinada marca é influenciada pelas preferências das pessoas com as quais ela interage socialmente) e expressiva de valor (o indivíduo acredita que a compra ou o uso de determinada marca promoverá a imagem que os outros têm dele). Já a família é a mais importante organização de compra de produtos de consumo na sociedade; os membros da família constituem o grupo de referência primária mais influente. $\mathrm{O}$ papel que cada um desempenha na sociedade, acompanhado de seu status, também interfere e influencia no 
comportamento de compra. Um exemplo seria o presidente de uma empresa: ele vai dar preferência a um terno de um corte mais fino e, logo, mais caro porque o papel que ele desempenha, acompanhado de seu status, sugere.

Os fatores pessoais reúnem a idade, estágio do ciclo de vida, ocupação, circunstâncias econômicas, estilo de vida, personalidade e autoimagem do consumidor. Os padrões de consumo são contornados a partir do ciclo de vida da família. Portanto, no caso particular, é natural que famílias com crianças pequenas busquem escolas que ofereçam serviço de creche o que, antes do nascimento dos filhos, não era um padrão esse consumo.

Já outro fator que afeta extremamente a escolha do produto, que poderá ser um bem ou serviço, são as circunstâncias econômicas: renda disponível, economias e bens, débitos, capacidade de endividamento e atitude em relação a gastar versus economizar. Pessoas de mesma subcultura, classe social e ocupação, ainda assim, podem ter estilos de vida bem diferentes - ou seja, um padrão de vida expresso por atividades, interesses e opiniões (KOTLER, 2000).

Quanto à personalidade, conceituada como o conjunto de características psicológicas distintas que levam a reações relativamente coerentes e contínuas no ambiente, Kotler (2010) afirma que toda pessoa tem uma distinta, que influencia seu comportamento de compra. Esta pode ser uma variável útil para se analisar o comportamento do consumidor uma vez que os tipos de personalidade podem ser classificados com precisão e que existem fortes correlações entre certos tipos de personalidade e as escolhas de produtos e marcas. Uma escola de educação infantil pode, a partir de um estudo aplicado ao mercado, identificar que grande parte de seus clientes demonstram autoconfiança e autonomia, logo, deve levar em consideração tais aspectos e as essas características dos clientes, justamente para que a autoimagem da escola vá ao encontro do seu público-alvo.

Por fim, os fatores psicológicos envolvem a motivação, a percepção, a aprendizagem e crenças e atitudes do consumidor. Uma determinada pessoa tem uma percepção de uma situação - essa percepção influencia diretamente o modo como ela age, e essa ação (esse "agir") é tomada a partir de uma necessidade, um motivo importante. Ou seja, o motivo é uma necessidade que é suficientemente importante para levar o indivíduo a agir e a maneira como a pessoa (já motivada) age é influenciada pela percepção que ela tem da situação. Quando as pessoas agem, elas aprendem e, fazendo e aprendendo, adquirem crenças e atitudes que, por sua vez, influenciam no seu comportamento (KOTLER, 2010).

As pessoas podem comprar produtos não pelo o que eles fazem, mas pelo que eles significam. Este princípio não significa que a função básica de um produto não tenha importância, mas que os papéis que os produtos exercem em nossa vida transcendem em muito as funções que realizam (SOLOMON, 2016).

O motivo pode ser definido como uma condição interna relativamente duradoura que leva o indivíduo ou que o predispõe a persistir num comportamento orientado para um objetivo, possibilitando a transformação ou a permanência de situação (SAWREY; TELFORD, 1976 apud KARSAKLIAN, 2000).

Para Kotler (2000, p. 195), “a percepção é o processo por meio do qual uma pessoa seleciona, organiza e interpreta as informações recebidas para criar uma imagem que ela tem da situação". Segundo o mesmo autor, as pessoas podem ter diferentes percepções do mesmo objeto devido a três processos. A atenção seletiva é um deles; como é impossível se lembrar de todas as informações e anúncios que as pessoas são expostas diariamente, a maioria dos estímulos é filtrada. Já a distorção seletiva é a tendência em transformar a informação e a mensagem em significados pessoais e interpretá-la de maneira que se adapte a seus 
prejulgamentos. E, por fim, a retenção seletiva, no qual as pessoas esquecem muito do que veem, mas tendem a reter informações que sustentam suas crenças e atitudes.

A aprendizagem envolve mudanças no comportamento de uma pessoa surgidas da experiência; já as crenças são pensamentos descritivos que uma pessoa mantém a respeito de alguma coisa, e podem ter como base conhecimento, opinião ou fé. Tão importante quanto às crenças são as atitudes. Uma atitude corresponde a avaliações, sentimentos e tendências de ação duradouras, favoráveis ou não, a algum objeto ou ideia (KOTLER, 2000). Segundo o mesmo autor, o tipo do produto ou serviço a ser comprado implica em decisões bastante diferentes. As compras complexas e caras envolvem, geralmente, maior ponderação do comprador e maior número de participantes.

De acordo com Assael (1992 apud KOTLER, 2000), destacam-se quatro tipos de comportamento de compra do consumidor baseados em seu grau de envolvimento e o grau de diferenças entre as marcas. O Quadro 1 sintetiza o envolvimento do consumidor e o grau de diferença entre as marcas, tornando assim diferentes tipos de comportamentos básicos.

Quadro 1. Os tipos de comportamento de compra

\begin{tabular}{lll}
\hline & \multicolumn{1}{c}{ Alto envolvimento } & \multicolumn{1}{c}{ Baixo envolvimento } \\
\hline $\begin{array}{l}\text { Diferenças significativas } \\
\text { entre marcas }\end{array}$ & $\begin{array}{l}\text { Comportamento de compra } \\
\text { complexo }\end{array}$ & $\begin{array}{l}\text { Comportamento de compra em } \\
\text { busca de variedade }\end{array}$ \\
$\begin{array}{l}\text { Poucas diferenças entre } \\
\text { marcas }\end{array}$ & $\begin{array}{l}\text { Comportamento de compra com } \\
\text { dissonância cognitiva reduzida }\end{array}$ & $\begin{array}{l}\text { Comportamento de compra } \\
\text { habitual }\end{array}$ \\
\hline
\end{tabular}

Fonte: Kotler (2000, p. 199)

\section{O processo de tomada de decisão de compra}

Vários fatores influenciam o comportamento de compra, seja de um bem ou de um serviço, como é o caso deste estudo. Já no processo de decisão de compra, além dos diferentes estágios que se percorre entre o reconhecimento do problema até o comportamento pós compra, é necessário que se identifique quais os papéis do comprador e qual o tipo de comportamento de compra (KOTLER, 2000).

De acordo com a teoria dos papeis, numa perspectiva sociológica, Solomon (2016) afirma que o comportamento do consumidor lembra cenas de uma peça teatral. Conforme são os diferentes papeis que as pessoas "encenam" na sociedade, assim também será a sua forma de consumir. Enquanto desempenha um determinado papel, uma pessoa pode avaliar um produto de forma completamente diferente caso estivesse desempenhando outro papel. Um indivíduo poderia, no papel de homem de negócios, avaliar satisfatoriamente um produto, enquanto este mesmo homem, agora enquanto pai, pode ter uma avaliação diferente do mesmo produto. Justamente por isso a importância das empresas se atentarem a essa teoria para conseguir satisfazer cada "ator" naquilo que ele busca, seja qual for o seu papel.

Contribuindo para esse conceito, acrescenta-se Jung e o arquétipo (uma das principais estruturas da personalidade) da Persona. Segundo esse, a persona é a forma pela qual as pessoas se apresentam ao mundo; é o caráter que assumem. É através dela que se relacionam com os demais. De acordo com Santana (2005), a palavra vem do grego e representava, originalmente, a máscara utilizada pelos atores para designar o papel que representavam. Na psicologia Junguiana, o arquétipo da persona também tem uma função próxima, "dá ao indivíduo a possibilidade de compor um personagem que necessariamente não é ele mesmo" (HALL; NORDBY, 2000, p.36). Em outras palavras, Grinberg (1997, p. 142) afirma que "como máscara, o arquétipo da persona diz respeito principalmente ao que é esperado socialmente de uma pessoa e à maneira como ela acredita que deva parecer ser. Trata-se de um compromisso 
entre o indivíduo e a sociedade". Como Santana (2005) alega, a persona tem a importante função de revelar aos outros como a pessoa deseja ser vista.

De acordo com Kotler (2010, p. 199), é possível distinguir cinco papeis que as pessoas podem desempenhar em uma decisão de compra:

\author{
a) Iniciador: quem sugere a ideia de comprar um produto ou serviço; \\ b) Influenciador: pessoa cujo ponto de vista ou conselho influencia na decisão; \\ c) Decisor: quem decide sobre quaisquer componentes de uma decisão de \\ compra: comprar, o que, como ou onde; \\ d) Comprador: quem, efetivamente, realiza a compra; \\ e) Usuário: quem consome ou usa o produto ou serviço.
}

Efetuar uma compra é um processo complexo, que envolve diversas e diferentes etapas que vão além da simples entrega do produto. Para cada produto, bem ou serviço, conforme já mencionado anteriormente, a tomada de decisão será completamente diferente. Toda decisão de consumo que as pessoas tomam é uma resposta a um problema.

Solomon (2016) chama o processo do pensamento para a tomada de decisão de processamento construtivo, onde é avaliado o esforço do qual será necessário para fazer a escolha específica e, depois, ajustar a quantidade de "esforço" cognitivo para tomar uma decisão. Ainda de acordo com o autor, deve-se considerar três diferentes perspectivas de tomada de decisão.

Figura 2: Processo de tomada decisão de compra

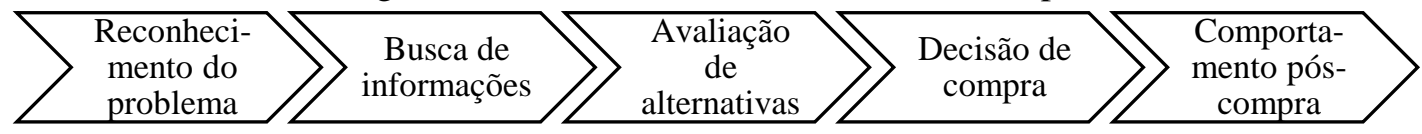

Fonte: Kotler (2000, p.201)

Em circunstâncias de alto envolvimento cognitivo, as pessoas tendem a pensar com cuidado nos prós e contras das diferentes opções, de modo muito semelhante a um computador que segue uma fórmula um tanto complexa para tomar uma decisão. Segundo Kotler (2000, p. 203), "o consumidor toma atitudes (julgamentos, preferências) relacionadas com várias marcas por meio de um procedimento de avaliação de atributos", ou seja, ele avalia diversos produtos diferentes a partir de seus atributos.

Acrescentando um item às etapas do processo de decisão proposto por Kotler (2000), Solomon (2016) frisa a importância dos critérios de avaliação para que este processo seja completo. Segundo o autor, estes critérios "são as dimensões utilizadas para julgar os méritos de opções concorrentes" (SOLOMON, 2016, p. 55), ou seja, apenas uma forma de destrinchar o que já havia sido dito acima. Esses critérios, em que os produtos diferem uns dos outros, têm um peso maior no processo de decisão do que aqueles em que as alternativas são semelhantes. Quando a escolha do produto/serviço exige alto envolvimento cognitivo, as pessoas tendem a pensar mais antes de tomar sua decisão, analisando cada pró e contra - assim como um computador segue uma fórmula complexa. Quando a escolha é corriqueira - habitual ou emocional, há a probabilidade de se utilizar uma regra não compensatória. Ou seja, a rejeição de imediato de uma opção simplesmente por não agradar ou não for adequada (SOLOMON, 2016). Para Solomon (2016), regra não compensatória é aquela na qual o consumidor desconsidera opções de produtos e serviços por não estar familiarizado com eles, além de não estar motivado o suficiente para processar informações complexas, optando por regras mais simples para decidir. Elas são descritas conforme o Quadro 2.

Como já citado, pode-se tomar decisões de compra, além da forma racional, de forma habitual (automática) e afetiva (emocional). A primeira refere-se a escolhas feitas com pouco ou nenhum esforço consciente - escolhas feitas instantânea e rotineiramente, e traz uma solução 
satisfatória (aceitável). Já a segunda, são escolhas feitas baseadas na alteração dos estados de ânimo das pessoas ou através de associações dos produtos com uma resposta afetiva, sem análise de opções.

Quadro 2: As regras não compensatórias para escolha do produto

\begin{tabular}{ll}
\hline \multicolumn{1}{c}{ Regra } & \multicolumn{1}{c}{ Conceito } \\
\hline Lexicográfica & $\begin{array}{l}\text { Seleciona a melhor marca no atributo mais importante. Quando a pessoa considera } \\
\text { duas ou mais marcas igualmente satisfatórias naquele atributo, ela as compara no } \\
\text { segundo atributo mais importante. Este processo de seleção continua até que haja } \\
\text { desempate }\end{array}$ \\
Eliminação por aspectos & $\begin{array}{l}\text { O comprador avalia as marcas quanto ao atributo mais importante. Porém, ele impõe } \\
\text { pontos de corte específicos (atributos determinantes). }\end{array}$ \\
Enquanto as duas anteriores requerem o processamento por atributo, esta requer o \\
processamento por marca. Como no procedimento de eliminação por aspectos, o \\
tomador de decisão estabelece pontos de corte para cada atributo. Ele escolherá uma \\
marca se ela satisfizer todos os pontos de corte, mas rejeitará aquela que não \\
conseguir satisfazer nenhum deles.
\end{tabular}

Fonte: Solomon (2016, p.57)

\section{PROCEDIMENTOS METODOLÓGICOS}

A pesquisa científica é uma atividade humana, cujo objetivo é conhecer e explicar os fenômenos, fornecendo respostas às questões significativas para a compreensão da natureza. Para essa tarefa, o pesquisador utiliza o conhecimento anterior acumulado e manipula cuidadosamente os diferentes métodos e técnicas para obter resultado pertinente às suas indagações (PRODANOV; FREITAS, 2013). Na busca pela resposta satisfatória ao problema de pesquisa, adota-se como princípio diferentes pontos de vista: interno e externo, pela perspectiva da empresa e dos clientes. De acordo com os autores já mencionados acima, ambas as pesquisas se classificam como aplicadas quanto a sua natureza, pois objetivam gerar conhecimentos para aplicação prática, dirigidos a solução de problemas específicos (PRODANOV; FREITAS, 2013). No caso deste estudo, responder à questão problema através das duas etapas de coleta de dados, uma qualitativa e outra quantitativa.

A primeira fase, considerada qualitativa quanto à abordagem do problema (PRODONAV; FREITAS, 2013), encontrando-se em fase preliminar e proporcionando mais informações sobre o assunto - já que será a primeira abordagem ao objeto de estudo, visa aprofundamento quanto ao caso estudado e a pesquisa quanto à gestão do comportamento dos consumidores.

Para tanto, adota a técnica de estudo de caso (PRODANOV; FREITAS, 2013) porque consiste em coletar e analisar informações sobre determinado indivíduo a fim de estudar aspectos variados de sua vida, de acordo com o assunto da pesquisa. O método do estudo de caso "... não é uma técnica específica. É um meio de organizar dados sociais, preservando o caráter unitário do objeto social estudado" (GOODE; HATT, 1969, p. 422). Aqui pode ser um ponto limitador do estudo, uma vez que o estudo não pode ser generalizado a todas as escolas, já que se trata apenas de uma delas; e isso, para alguns autores, é uma limitação.

Quanto ao objetivo desta pesquisa, a primeira fase apresenta-se como explicativa, pois visa "identificar fatores que determinam a ocorrência de fenômenos. Explica a razão, o porquê das coisas" (GIL, 2002, p.42). Logo, serão observadas atitudes administrativas da gestão que poderão conduzir ao conhecimento de como a escola se evidencia aos seus clientes. A coleta dos dados foi realizada por meio de um roteiro semiestruturado para entrevista em profundidade com a sócia-diretora da escola. Nesse caso, o roteiro foi ordenado em vinte e sete questões, 
dividido em seis blocos, sendo o primeiro: o perfil do entrevistado, o segundo: a identificação da história da empreendedora, o terceiro: as perspectivas de mercado, o quarto: os clientes, o quinto: atributos e compra e o sexto e último: a escola.

Ao fim da primeira coleta, dá-se o seguimento a segunda etapa da pesquisa, voltada ao público-alvo externo, ou seja, os clientes da organização. Referente à abordagem do problema, esta fase do estudo classifica-se como quantitativa, pois podem ser quantificados.

Classificada como descritiva quanto aos objetivos de pesquisa, esta fase do estudo tem como objetivo primordial o estabelecimento de relações entre variáveis (GIL, 2002, p.42). Pretende relacionar o comportamento dos pais enquanto consumidores e sua satisfação com a escola.

Quanto ao procedimento técnico de coleta, esta segunda etapa adota o levantamento, pois será lidado diretamente com pessoas cujo comportamento é desejável conhecer a partir de um questionário estruturado. Entre as principais vantagens dos levantamentos, estão: conhecimento direto da realidade; economia e rapidez; quantificação (PRODANOV; FREITAS, 2013).

Para a descrição dos fatores e preferências ligadas ao estudo do comportamento, utilizase um questionário estruturado, em sua maioria por perguntas fechadas - todas relacionadas com questões já mencionadas à gestora da escola. Construído a partir da organização conceitual marcada no referencial teórico, que retrataram o estudo do comportamento de consumo baseado em Kotler (2000), Solomon (2016) e Peter e Olson (2009).

O público-alvo dessa etapa de coleta de dados é formado pelos pais, mães e responsáveis pela educação escolar das crianças matriculadas na escola; a partir do banco de dados de endereço eletrônico destes responsáveis, de posse da escola, foi enviada a pesquisa a todos eles - sem exceção - por e-mail, e reforçada através de comunicado nas agendas dos alunos para enfatizar a importância da pesquisa. O questionário foi construído a partir da fundamentação teórica, conforme já mencionado; com trinta questões divididas em três blocos distintos, sendo o primeiro sobre o perfil do entrevistado, o segundo sobre hábitos e comportamento de compra, e o último sobre satisfação com a escola. A maioria das questões foi fechada, deixando algumas abertas para que os pais pudessem se posicionar da maneira que achassem conveniente. Por se tratar de um público restrito - apenas os pais de alunos da escola de enfoque - o estudo é considerado não-probabilístico, cuja amostragem se dará pelo critério de conveniência. $\mathrm{O}$ Quadro 3, a seguir, sintetiza a organização metodológica do estudo:

Quadro 3: classificação das duas fases da pesquisa

\begin{tabular}{lcc}
\hline Variáveis & Etapa 1 & Etapa 2 \\
\hline Objetivos da pesquisa & Explicativa & Descritiva \\
Procedimento técnico & Estudo de caso & Levantamento \\
Abordagem do problema & Qualitativa & Quantitativa \\
Instrumento de coleta & Roteiro semiestruturado & Questionário estruturado \\
Público-alvo & Gestora da escola & Pais de alunos da escola \\
\hline
\end{tabular}

Fonte: Elaborado pelos autores, 2017.

Dentro do horizonte temporal de pesquisa, classifica-se este estudo como sendo de corte transversal, já que os dados foram coletados em apenas um ponto do tempo. A entrevista com a gestora foi realizada no dia 19/02/2017 e teve cerca de duas horas de duração. Posteriormente, foi transcrita para a realização da discussão por meio de análise de conteúdo. Já a etapa quantitativa teve os questionários aplicados aos responsáveis entre os dias 15 e 27/02/2017. Posteriormente, foram tabulados por meio de planilha eletrônica e apresentados e analisados de 
forma descritiva na próxima seção. A fim de preservar o anonimato do caso, o nome real da escola será referido no texto pelo termo "Escola X".

\section{APRESENTAÇÃO E DISCUSSÃO DOS DADOS}

Apresenta-se uma breve descrição do histórico da escola, além da visão da gestora a respeito das perspectivas do mercado, de seus clientes enquanto consumidores e da própria escola. Na sequência, são apresentadas as análises feitas a partir da pesquisa realizada com os pais dos alunos.

\section{Escola X: um empreendedorismo por vontade própria}

As atividades da escola foram iniciadas a partir do trabalho empreendedor da gestora em 1997, na cidade de Cuiabá. De acordo com a mesma, "se hoje ainda é uma escola pequena, ela começou bem pequenininha". No início, o espaço era uma residência adaptada para o berçário, que gradualmente foi crescendo para atender as séries que foram aumentando conforme cada ano.

A escola nasceu da necessidade pessoal da própria gestora que, ao mudar-se do Rio de Janeiro para Cuiabá, há trinta anos, chegou aqui sem parentes mais próximos ou alguém de confiança que pudesse auxiliá-la na criação do filho mais velho. Apesar de ter prolongado o máximo que pôde a gestação do segundo filho, quando esse veio, surgiu a ideia de criar um local que pudesse auxiliar mães que estivessem passando pela mesma situação. Foi um empreendedorismo por necessidade, pautado na demanda de mães - incluindo ela - que necessitavam dos serviços de uma creche. Na época, só havia na cidade uma escola referência nesse tipo de serviço, as demais eram apenas residências cuidadoras, nada de forma comercial.

Ela afirma que a maior dificuldade encontrada na época eram as referências - já que não possuíam sobrenome conhecido na cidade, que pudesse dar credibilidade ao trabalho desenvolvido; além da mão de obra. Atualmente, após vinte anos à frente da organização, ela alega que os aprendizados durante esses anos foram todos os possíveis, e que continua aprendendo sempre. A mesma reconhece que não começou gestora:

Eu digo que eu comecei sala de aula, não comecei escola. Porque sala de aula era o que eu achava que sabia fazer; era professora e achava que, como professora, eu poderia ter uma escola. E a coisa é um pouquinho mais. Eu comecei sala de aula, embora, na ocasião, minha primeira criança tivesse quatro meses; mas aí, era fácil trabalhar com o desenvolvimento infantil, era saber o quanto - na experiência de mãe - o quanto, onde poderia chegar, o que eu poderia fazer. Então foi fácil, por esse aspecto, mas tinha que crescer enquanto empresa, e crescer enquanto empresa aí foi mais doído porque antes de tudo tem que abandonar o romantismo, entrar na realidade. Então, por mais que eu quisesse a cada cinco crianças ter um funcionário, era inviável enquanto empresa. Precisava crescer enquanto empresa, precisava ter nome, ao mesmo tempo que precisava mostrar trabalho. Como é que você faz isso?

Da mesma forma, a diretora acredita que existe uma necessidade latente do mercado consumidor pelo serviço que ela continua a oferecer. Existe um motivo, que conforme elucidado por Sawrey e Telford (1976 apud KARSAKLIAN, 2000), pode ser definido como uma condição interna relativamente duradoura que leva o indivíduo - no caso, a mãe - a persistir num comportamento orientado para um objetivo (o da escolha de uma escola para colocar o filho), possibilitando a transformação ou a permanência de situação. 
Seja pelas próprias crianças (que continuam a nascer e a precisar de um local de estudo) ou pelas mães, que encontram na escola uma parceria nessa caminhada. Exemplificando a teoria dos papeis (SOLOMON, 2016) no serviço que se baseia esse estudo de caso, é importante que uma escola ofereça benefícios que possam agradar o papel da mãe (que se preocupa com o cuidado e bem-estar do filho), da executiva (que preza por horários flexíveis na escola, já que trabalha em período integral), da esposa (que busca valores que caibam dentro do orçamento familiar), assim por diante.

De acordo com a gestora, a tendência desse mercado é só ampliar, já que entre deixar uma criança em casa ou deixá-la num ambiente seguro e cognitivamente desafiador, a segunda opção é extremamente mais vantajosa - desde que as escolas acompanhem essa evolução. De acordo com uma pesquisa realizada pela Universidade de Oxford, no Reino Unido, acompanhando seis mil crianças de 2 a 7 anos, afirma-se que: "as crianças que entraram na escola mais cedo tiveram resultados positivos e muito significativos no desenvolvimento emocional e da linguagem”. Segundo os cientistas, por mais benéfica e produtiva que seja a aprendizagem promovida em casa - seja com babá ou outros cuidadores - a instituição de ensino traz benefícios ainda maiores.

Mas será que apenas colocar a criança na escola resolve o problema? Nesse aspecto, a escola tem a concepção de um grande depósito onde se é possível acomodar satisfatoriamente seu filho, de modo que ele não sofra nenhum tipo de dano até o momento em que você retorne para buscá-lo. Mas não é exatamente assim a relação pais e escola.

Estes pais encontraram na escola uma aliada na criação de seus filhos. Se antes era possível - e natural - que a mulher deixasse de lado sua carreira para se dedicar com exclusividade à maternidade, hoje essa visão já não é tão bem aceita entre o público feminino. Isso porque, segundo a diretora do Departamento de Ações Programáticas Estratégicas do Ministério da Saúde, Thereza de Lamare, "o Brasil segue uma tendência observada em países desenvolvidos, com a inserção ainda mais forte da mulher no mercado de trabalho, com mais acesso aos métodos anticoncepcionais. Com isso, a mulher planeja melhor sua gravidez".

Logo, a escola torna-se um segundo lar desta criança, onde ela passa a ocupar, muitas vezes, mais tempo nesse estabelecimento do que em sua própria residência. E a relação escola e pais torna-se um vínculo de parceria, onde a interação da família com a instituição torna-se constante e íntima. Quanto às ameaças, a gestora acredita que a concorrência é um fator predominante para escolas da rede privada; porém, ela faz uma observação importante:

\footnotetext{
Na rede privada, eu acredito que sempre existe uma ameaça, mas a ameaça, ela é muito mais em função arquitetônica do que em qualidade do trabalho. Porque a qualidade do trabalho bem-feita, um trabalho pensado realmente na educação, na construção do conhecimento, ele é feito com muito pouco. Mas, influencia aí o nome, a tradição, a idade da escola, o que pode oferecer, de repente, extraclasse, então isso eu percebo que existe uma concorrência.
}

Como já foi mencionado anteriormente, onde o consumidor tenderá a escolher um produto que corresponda ao conceito que ele tem ou que gostaria de ter de si mesmo (KARSAKLIAN, 2000), logo, as pessoas podem comprar produtos não pelo o que eles fazem, mas pelo que eles significam (SOLOMON, 2016) - e uma escola com um espaço físico maior significa mais status.

Conforme a entrevistada, o mercado de vinte anos atrás era formado, basicamente, por um público de pais com maior idade, mais estabilizados na carreira e, consequentemente, financeiramente, além de mais preocupados com o futuro da criança; atualmente, esses pais além de mais novos e menos estabelecidos financeiramente, estão menos preocupados, 
acreditam que basta a criança estar na escola "está bom: está bonitinho, está limpinho, está organizadinho... Está ótimo!". Se antes esses pais vinham para a escola exclusivamente através de indicações, por ser algo pessoal e de extrema importância - já que se tratava de uma escolha de alto envolvimento, sendo um comportamento de compra complexo (KOTLER, 2000), hoje, esses pais chegam, além das indicações, por meio da comunicação de massa. Infere-se que seja um comportamento de compra com dissonância cognitiva reduzida, quando há pouca diferença entre as marcas.

Esse é o perfil do segmento de clientes-alvo da escola - pais, em sua maioria em início de casamento, recém-formados e das classes A e B. Porém, a gestora faz uma observação quanto ao perfil deste cliente e a escolha da escola: "é o que eu sempre digo: não basta só poder pagar a mensalidade, é um contexto, sabe? Então, a coisa precisa atingir essa criança, atingir essa família na essência". O comportamento de compra sofre influência justamente por fatores culturais (classe social) e pessoais (idade, estágio do ciclo de vida, ocupação, circunstâncias econômicas), entre outros. Além disso, há outro forte influenciador: grupos do aplicativo de mensagens Whatsapp formados por mães que se revezam para conhecer escolas; algumas delas acabam fazendo o papel de influenciadoras das demais quando gostam ou não de determinada instituição, num claro papel de líderes (KOTLER, 2000). Percebe-se que todo este perfil de pais se encontra sob o mesmo prisma destes fatores.

Apesar da escola já estar há vinte anos no mercado, a gestora confessa nunca ter realizado nenhum tipo de pesquisa de mercado antes, tampouco acompanhado o comportamento de compra de seus clientes, mas observa que quem chega até ali "já chega com bons carros, boas joias, boas bolsas, já chegam muito dentro desse quadrado (...) Agora, se ele não pagou o carro, a gente também sabe: porque ele não paga a escola".

Conforme a fala da gestora, durante o processo de escolha de uma escola, os pais chegam muito bem informados, diferente de antigamente. Geralmente vêm pautados em indicações, no que veem na mídia e no dia a dia, mas, dificilmente sabem o que querem.

Dificilmente um pai pergunta sobre metodologia - até porque poucos conhecem. As pessoas ainda procuram muito escola baseado no vizinho, no chefe, no doutor fulano, na senhora tal que botou lá o neto - em referências de pessoas. Mas, dificilmente, é: "eu quero uma escola tal!".

A fala da diretora vai ao encontro do processo de tomada de decisão que Kotler (2000) desenha, onde, após o primeiro passo, que é o reconhecimento do problema, passa-se ao segundo passo, ou seja, a busca de informações, tanto pessoais (de familiares e amigos), como experimental (aqui, no caso, o próprio ato de visitar a escola). Além, claro, da influência dos fatores sociais neste comportamento de compra, como os grupos de referência e o status que isso traz (KOTLER, 2000).

Um pai nunca veio pelo método sócio interacionista. Aí ele vem influenciado por um marketing, baseado no Sistema Positivo de Ensino. Como se o Sistema Positivo de Ensino fosse metodologia. É um material que pra gente, escola, a gente usa porque, enquanto escola tem assessoria jurídica boa, assessoria de marketing boa, as orientações para o professor. Mas, em termos de material, é um material que atende qualquer escola, da mais comprometida com a menos comprometida, qualquer metodologia.

A importância da comunicação se faz presente nestes momentos, onde o marketing influencia na tomada de decisão deste pai através da mídia, do apelo, do que é conhecido - o Sistema Positivo de Ensino - onde se permite fazer um paralelo na forma de interpretação das informações, segundo Peter e Olson (2006). Justamente o diferencial, a comunicação, que pode 
desencadear a escolha de uma escola em detrimento da outra, em fazer com que seja mais lembrada do que outra. Apesar da fala da diretora enfatizar que os fatores que fazem com que os clientes optem por uma escola ao invés de outra são diferentes (na opinião dela), sendo eles: a estrutura física, o tempo da escola e o fato do pai já ter estudado lá; reforçando, novamente, a influência por fatores externos na tomada de decisão (ocupação e circunstâncias econômicas, além de estilo de vida).

Parece lógico afirmar que é única e exclusivamente a mãe quem decide a escola dos filhos, independentemente de qualquer variável. Entretanto, essa é uma análise superficial, pois, de acordo com o que foi relatado até aqui, pode-se observar a existência de outros fatores que influenciam o comportamento e quem, de fato, exerce o papel de decisor.

Quanto aos papeis do comprador (KOTLER, 2000), cinco no total, na maioria das vezes o papel feito pelo iniciador, pelo decisor e pelo comprador são sempre feitos pela mesma pessoa: a mãe. É ela quem sugere a escola, busca informações, realiza a decisão de compra e efetivamente executa a compra, conforme fala da gestora. Ela narra que ainda fica muito a critério das mães, mas normalmente a visita até a escola e na decisão final da realização da matrícula vem o casal em mais de $50 \%$ dos casos. Mas a última palavra acaba sendo da mãe. Contudo, apesar de que, quando o perfil da família é mais aberto, elas acabam levando em consideração - e muito - a opinião do usuário, da criança, de acordo com a gestora.

Atualmente, a Escola $X$ oferece todos os serviços de educação e cuidado inerentes à criança desde seus quatro meses até completar dez anos, desde o berçário ao quinto ano. A diretora reconhece que não possui uma ampla estrutura física, mas o diferencial da escola está justamente na questão do ensino:

É um caderno corrigido; é um texto lido, corrigido e recorrigido; é uma avaliação não pra dar nota pra criança, mas sim pra avaliar o trabalho que a criança está internalizando em sala de aula, sem que ela esteja decorando (...) então é esse o diferencial. Mas, pra saber, tem que estar aqui dentro.

Além disso, alega que seus atributos são o seu diferencial: responsabilidade e compromisso. Segundo a mesma, o que a diferencia das demais escolas do mercado é em quantidade de professores, de mobiliário - o que ela não tem como competir, já que não tem como crescer. Mas que se faz notar onde, para ela, realmente importa: naquilo que se comprometeu com a criança, a educação. Estes pontos abordados pela gestora têm força suficiente para serem transformados em argumentos de comunicação.

Atualmente, a escola conta com site, fanpage em rede social, mídia em rádio líder de audiência e distribuição de panfletos na região próxima à escola, além de um painel outdoor numa movimentada rua próxima à instituição. Porém, nunca mediu ou realizou nenhum tipo de pesquisa de satisfação com seus clientes - apesar de já ter feito capacitação com o SEBRAE (Serviço Brasileiro de Apoio às Micro e Pequenas Empresas), onde foi incentivada a fazer este exercício de mensuração. A forma como avalia o nível de satisfação de seus clientes é através do índice de rematrícula e alguns relatos de clientes que pesquisa informalmente. Mas, nas palavras da diretora:

Não é porque as rematrículas acontecem que a escola se acomoda. Aquela filosofia: não é porque está bom que você vai sentar em cima do rabo. Mantendo tudo aquilo que a gente promete, mantendo aquilo que foi vendido para o cliente quando ele entrou aqui. Ele comprou o que? (...) então aquilo que a gente promete, é o que a gente vem tentando fazer. 
Não por menos, todos os clientes que chegam, vêm por indicação de alguém que já é cliente - reforçando, assim, a ideia da escala de lealdade, com clientes divulgadores - aqueles que testemunham sobre o tratamento recebido (RAPHEL, 1999).

\section{A ESCOLA PELO PONTO DE VISTA DO SEU CLIENTE}

Para análise dos resultados obtidos por intermédio do questionário aplicado aos pais dos alunos, serão apresentados a seguir os dados quantitativos sobre o seu comportamento de compra e o nível de satisfação com a escola.

Durante o período de aplicação do questionário, foi encaminhado por e-mail o convite para a pesquisa. Além disso, os pais foram sensibilizados quanto à participação via contato pessoal pelos funcionários da escola e por lembretes enviados junto às agendas dos estudantes. Após o tratamento das respostas, obteve-se o total de trinta e sete questionários completos. Esses, conforme apresentado no Quadro 4, a seguir, são compostos, em maior parte, por respondentes mulheres, com idade entre trinta e quarenta anos, funcionárias públicas, pósgraduadas, casadas e pertencentes à classe B. Não se pode generalizar e considerar esse o perfil de todo o segmento de clientes da escola, uma vez que se refere unicamente ao perfil majoritário dos que responderam à pesquisa.

Quadro 4 - Descrição do gênero, idade, profissão, escolaridade, ciclo de vida e renda.

\begin{tabular}{|c|c|c|}
\hline Variáveis & Frequência & $\%$ \\
\hline \multicolumn{3}{|l|}{ Gênero } \\
\hline Masculino & 8 & $21,62 \%$ \\
\hline Feminino & 29 & $78,38 \%$ \\
\hline \multicolumn{3}{|l|}{ Idade } \\
\hline Entre 30 e 40 anos & 23 & $62,16 \%$ \\
\hline Entre 41 e 50 anos & 13 & $35,14 \%$ \\
\hline Acima de 51 anos & 1 & $2,70 \%$ \\
\hline \multicolumn{3}{|l|}{ Profissão } \\
\hline Funcionário público & 17 & $45,95 \%$ \\
\hline Funcionário empresa & 5 & $13,51 \%$ \\
\hline Empresário & 3 & $8,11 \%$ \\
\hline Aposentado ou do lar & 4 & $10,81 \%$ \\
\hline Prestador de serviço/ autônomo & 4 & $10,81 \%$ \\
\hline Profissional liberal & 4 & $10,81 \%$ \\
\hline \multicolumn{3}{|l|}{ Escolaridade } \\
\hline Até o Ensino Fundamental & 1 & $2,70 \%$ \\
\hline Ensino Médio & 2 & $5,41 \%$ \\
\hline Graduado & 9 & $24,32 \%$ \\
\hline Pós-graduado & 25 & $67,57 \%$ \\
\hline \multicolumn{3}{|l|}{ Ciclo de vida } \\
\hline Solteiro com filhos & 4 & $10,81 \%$ \\
\hline Casado com filhos & 31 & $83,78 \%$ \\
\hline Divorciado & 2 & $5,41 \%$ \\
\hline \multicolumn{3}{|l|}{ Renda salarial familiar } \\
\hline Até $\mathrm{R} \$ 1.624,99$ & 0 & $0 \%$ \\
\hline Entre $R \$ 1.625,00$ e $R \$ 2.704,99$ & 1 & $2,70 \%$ \\
\hline Entre $R \$ 2.705,00$ e $R \$ 4.851,99$ & 5 & $13,51 \%$ \\
\hline Entre $\mathrm{R} \$ 4.852,00$ e $\mathrm{R} \$ 9.253,99$ & 9 & $24,32 \%$ \\
\hline Entre $R \$ 9.254,00$ e $R \$ 20.887,99$ & 13 & $35,14 \%$ \\
\hline Acima de $\mathrm{R} \$ 20.888,00$ & 9 & $24,32 \%$ \\
\hline
\end{tabular}

Fonte: Dados da pesquisa, 2017. 
Em relação aos influenciadores, constata-se - conforme Gráfico 1 - que a decisão quanto à escolha da escola, em sua maioria, partiu dos próprios pais. Há uma pequena parcela de influência partindo de amigos e colegas, familiares e até do próprio aluno. Quanto à opção "outros", surgiu a indicação da escola através da psicóloga de um dos alunos e também de pesquisa de escolas. Mas nada que denote algo notável ou fora do contexto. Observa-se influência dos grupos de referência (fatores sociais), aqui, apesar da atuação dos pais ser mais incisiva (KOTLER, 2000).

Gráfico 1: Principal agente de influência na decisão de escolha da escola

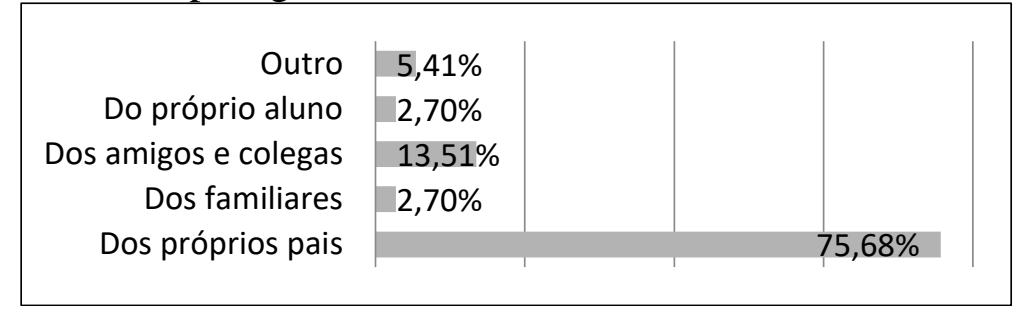

Fonte: Dados da pesquisa, 2017.

Durante a busca de informações na escolha da escola, entre os entrevistados, não houve menção alguma sobre pesquisa na internet. A maioria das buscas se fez através de fontes pessoais, indicações e grupos de referência (KOTLER, 2000) e indo diretamente na escola.

Ainda investigando mais a fundo sobre a escolha da escola, foram listadas algumas ações realizadas durante a tomada de decisão para que os pais marcassem todas aquelas que eles estavam habituados a realizar, justamente para identificar qual o trajeto que eles percorreram entre a identificação do problema, a busca de informações, a avaliação de alternativas até o momento da decisão da compra (KOTLER, 2000). A seguir, no Gráfico 2, apresentam-se os resultados. Das sete possibilidades listadas, três delas foram as mais executadas: realização de visitas em escolas, pesquisa com pessoas próximas (grupos de referência) e uma decisão pautada em planejamento e pesquisa preliminar. Todos os respondentes buscaram de forma ativa as informações sobre o produto, sobre a escola, conforme Kotler (2000).

Para complementar esta pergunta, foi feita uma adicional, questionando os pais sobre a quantidade (em média) de escolas visitadas durante o processo de escolha da instituição, conforme o Gráfico 2. Mais de 70\% dos respondentes visitaram entre três e cinco escolas antes de tomar sua decisão. Infere-se um forte indício de que, de fato, a busca por informações e a avaliação de alternativas são passos fundamentais antes da escolha, já que esta é uma decisão de compra com alto envolvimento. Conforme já mencionado, as compras complexas envolvem, geralmente, maior ponderação do comprador e maior número de participantes (KOTLER, 2000).

Outra questão bastante importante abordada durante a pesquisa com os pais está relacionada aos atributos e características de escolha de uma escola em detrimento de outra; quais fatores de influência levam à escolha de uma instituição de ensino - conforme observase no próximo quadro. Constata-se que o ensino e estímulo religioso, a oferta de bolsas e descontos, além da localização são três pontos que os pais valorizam menos na hora da escolha - apesar da dispersão nas opiniões sobre a oferta de bolsas e descontos ter ficado acima das demais. O segundo item, talvez, por se tratar de pais de classe média e alta (A e B), conforme revelou a pesquisa (fator pessoal) (KOTLER, 2000). 
Gráfico 2: Ações realizadas durantes a tomada de decisão.

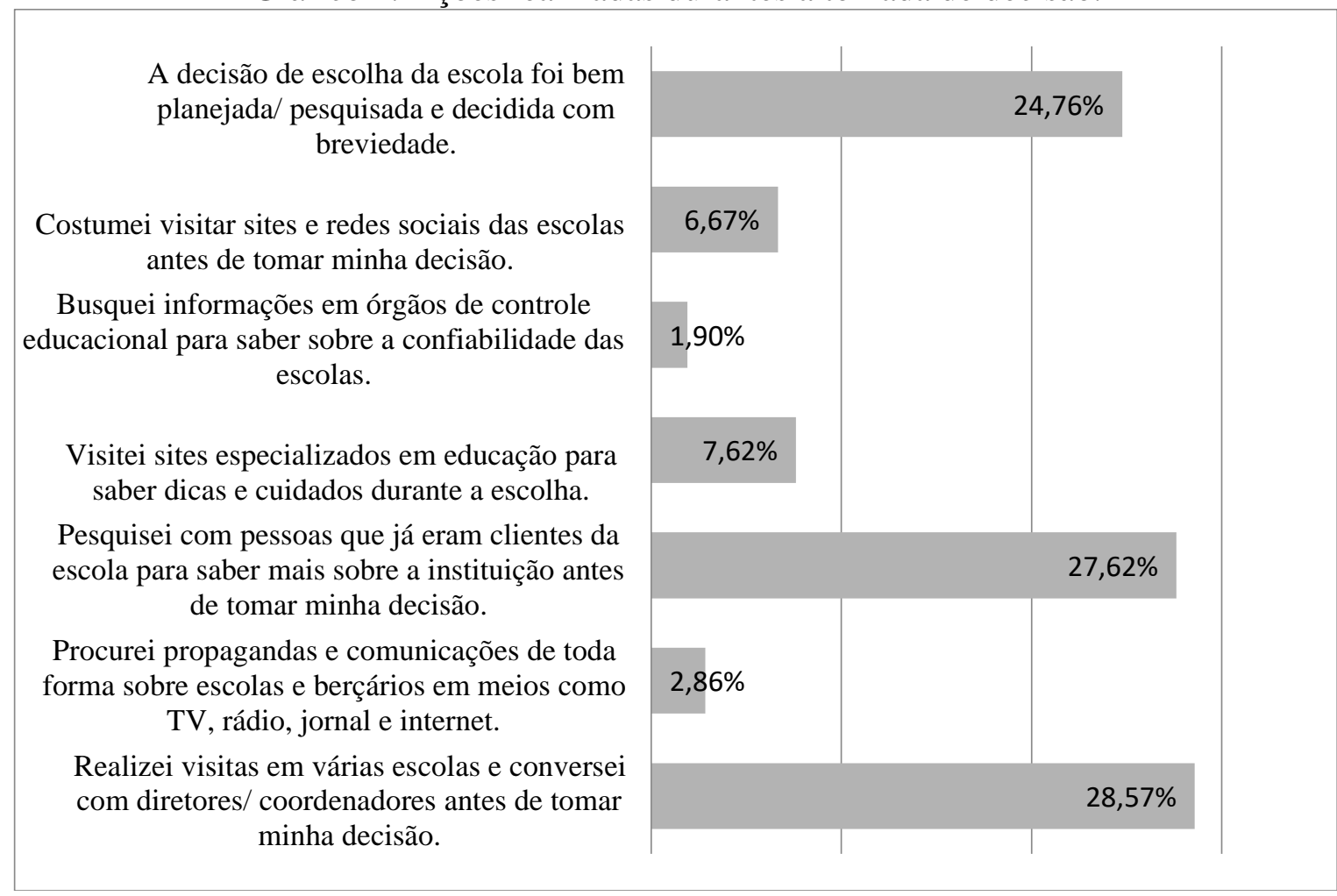

Fonte: Dados da pesquisa, 2017

Porém, a equipe de professores e educadores, a metodologia pedagógica e material didático, além da segurança e controle dentro das dependências da escola fícam, respectivamente, em primeiro, segundo e terceiro lugar na ordem de preferência e de observância destes pais; e, vale frisar, com baixa dispersão. Pode-se inferir que estes quesitos, entre os respondentes, são os de maior importância durante a escolha da escola. Os dois primeiros voltados para a educação da criança - que é, de fato, o que os pais buscam numa escola e, o segundo, de acordo com a teoria de Maslow (KARSAKLIAN, 2000), a necessidade de segurança, oferecida pela escola que nada mais é do que o "segundo lar da criança".

O Quadro 5 inicia a seção de número três do questionário, referente à satisfação do cliente com a escola.

No final, verifica-se a média de satisfação dos clientes com cada item pautado, conforme Quadro 6. Porém, apesar dessas médias neutras (apesar de todas elas serem acima de 3,2), quando questionados a respeito da chance de recomendar a escola a terceiros, o score foi alto $(4,78)$ com um desvio padrão baixo $(0,48)$. A Escola X é uma escola com índices satisfatórios entre os seus clientes. 
Quadro 5 - Principais atributos e características valorizadas para escolha da escola

\begin{tabular}{lcc}
\hline \multicolumn{1}{c}{ Variáveis } & Média & Desvio Padrão \\
\hline Estrutura física (salas, espaço de lazer,...) & 4,51 & 0,51 \\
Localização (proximidade com local onde pai mora ou & 3,97 & 0,90 \\
trabalha) & & 0,28 \\
Equipe de professores e educadores & 4,92 & 0,43 \\
Segurança e controle dentro das dependências & 4,76 & 0,37 \\
Metodologia pedagógica (sistema de ensino) e material & 4,84 & 1,15 \\
didático & & 1,14 \\
Ensino e estímulo religioso & 3,51 & 0,76 \\
Ensino e abertura a diversidade cultural & 3,97 & 0,47 \\
Preço da mensalidade & 4,16 & 0,68 \\
Equipe diretiva e coordenadora da escola & 4,68 & 0,77 \\
Atendimento da escola e forma de comunicação com os & 4,62 & 0,75 \\
pais & & 0,65 \\
Oferta de atividades esportivas, artísticas e extraclasse & 4,27 & 1,06 \\
Tradição e reconhecimento no mercado & 4,14 & 4,43 \\
Número de alunos por turma & 3,62 & \\
Oferta de bolsas/ descontos & 2017. & \\
\hline
\end{tabular}

Fonte: Dados da pesquisa, 2017.

Quadro 6 - Satisfação dos clientes com a Escola X

\begin{tabular}{lcc}
\hline \multicolumn{1}{c}{ Variáveis } & Média & Desvio Padrão \\
\hline Estrutura física (salas, espaço de lazer,...) & 3,41 & 1,07 \\
Localização (proximidade com local onde pai mora & 3,81 & 1,29 \\
ou trabalha) & & \\
Equipe de professores e educadores & 3,65 & 1,42 \\
Segurança e controle dentro das dependências & 3,57 & 1,32 \\
Metodologia educacional (sistema de ensino) e & 3,84 & 1,32 \\
material didático & & 0,98 \\
Preço da mensalidade & 3,24 & 1,42 \\
Equipe diretiva e coordenadora da escola & 3,59 & 1,46 \\
Atendimento da escola (contato) e relacionamento & 3,78 & 1,04 \\
com os pais & & 0,48 \\
Propaganda e comunicação & 3,49 & 4,78 \\
Chance de recomendação da escola & 2017 & \\
\hline
\end{tabular}

Fonte: Dados da pesquisa, 2017.

Comparando um quadro com o outro (principais atributos que os pais buscam numa escola versus a satisfação com a escola $\mathrm{X}$ ), percebe-se que os seis principais atributos são os mesmos - com exceção de um - para ambos os resultados. Tudo aquilo que os pais buscavam numa escola, coincidem com o que destacam na escola $\mathrm{X}$.

Os motivos pelos quais os pais indicariam a escola foram equivalentes aos já mencionados anteriormente, quando indagados sobre o motivo pelo qual desejam manter os filhos na escola. Para finalizar o questionário, foram feitas mais três questões. Uma delas era se havia algum tipo de reclamação a fazer referente à escola - o que ocorreu com $38 \%$ dos entrevistados. Os motivos foram os mais variados possíveis: maior preparo dos monitores, falta de espaço físico, falta de comunicação interna (pais reclamaram que os comunicados veem apenas via e-mail, e alguns deles não acessam o endereço eletrônico diariamente), outros solicitam mais atividades extracurriculares.

Por fim, a título de sugestões, crítica ou comentário relativo a algum ponto abordado durante a pesquisa, observou-se novamente solicitações de estrutura física maior, abertura para descontos na mensalidade e sugeriram que esta pesquisa fosse repetida semestral ou 
anualmente. Os dados aqui analisados não têm intenção de definir os clientes da Escola X, apenas identificar quais fatores de influência - entre eles - são os principais pontos na hora da escolha de uma escola. Percebe-se que a entrevista da diretora converge em alguns pontos com a opinião dos clientes, uma forte indicação de que esta gestora está à frente da escola e, apesar de nunca ter feito pesquisas mais profundas, conhece seu público e, principalmente, sabe do diferencial do seu produto. Alguns pontos, a diretora salienta sua maior dificuldade (no caso, o espaço físico). Porém, a pesquisa revelou que este não é o fator que mais agrega atenção aos pais, na busca pela escola ideal de seus filhos - elencado na sexta posição, num total de catorze fatores.

\section{CONSIDERAÇÕES FINAIS}

O presente estudo pesquisou o comportamento de compra e o processo de escolha dos clientes da escola analisada. Também foi possível elencar os principais fatores críticos de sucesso da escola a partir da sua perspectiva de atuação; através da visão da gestora constatouse a convergência entre a opinião de pais e escola, numa caracterização de como se dá essa relação entre cliente e escola. Apurou-se os principais fatores de influência, durante o processo de escolha, e por meio de questionário, observou-se os hábitos destes pais e o que os mantém enquanto clientes da escola. Portanto, acredita-se que o estudo alcançou os objetivos pretendidos.

Resgatando a questão norteadora: quais são os fatores de influência que levam à escolha de uma instituição de ensino para educação de crianças? Observou-se que os pais buscam por fatores internos, do que a escola tem como oferecer enquanto instituição de ensino - de fato, muito mais do que por externos - como amplas salas, laboratórios, anfiteatro, entre outros. Isso significa dizer que a equipe de professores e educadores, a metodologia adotada pela escola, bem como o material didático, a segurança que o local oferece, a equipe diretiva e de coordenadores, bem como o atendimento que presta tanto ao aluno quanto aos pais são fatores muito mais básicos e essenciais do que a estrutura física em que ela está instalada.

Como resultados mais significativos, a resposta à questão problema foi uma delas, já que na visão da gestora, o espaço físico e a tradição das escolas mais antigas contariam muito mais do que o próprio método de ensino. Atualmente, os grupos de referência vão além dos familiares e vizinhos e passaram a ocupar um lugar virtual e incluir pessoas que, normalmente, mantêm-se pouco contato como o grupo de mães no Whatsapp, que pode influenciar diversas outras com apenas alguns comentários de percepções que tiveram durante uma visita numa determinada escola, ou seja, deixou-se de ter referência em quem se conhece para pessoas que acreditam estar mais capacitadas, seja por similitudes ou ciclo de vida (mulheres casadas, mães de família, com crianças pequenas e procurando escolas de qualidade que atendam suas exigentes necessidades). Apesar de Cuiabá ser uma cidade média, com mais de quinhentos e oitenta mil habitantes, a maioria dos clientes chegam até a escola por indicação - seja de amigos, de familiares, de professores, de outros pais. Quem vem, sempre tem alguma observação de alguém que lhe aconselhou ou que lhe fez notórias observações a respeito da instituição, mostrando a força - mais uma vez - dos grupos de referência.

E apesar da gestora nunca ter feito nenhum tipo de pesquisa que pudesse aprofundar sobre os hábitos e o comportamento de compra do seu cliente, ou a satisfação do mesmo, durante os vinte anos de existência da escola, a instituição tem se mantido como um dos principais nomes em referência de berçário e ensino fundamental na cidade. E por mais que o espaço físico não suporte o crescimento da escola, em número de alunos superior ao que comporta atualmente, esta se mantém, quando não com sua capacidade máxima, bem próxima 
disso. A partir da análise e da discussão, inferiu-se diversas constatações a respeito de hábitos de consumo e de compra no universo de escolas. Porém, os resultados representam apenas o caso pesquisado. Logo, os resultados da pesquisa não podem ser generalizados e representar todo o segmento. Uma limitação do estudo consiste na amostra de pais que responderam à pesquisa. Futuros estudos podem considerar pais de diferentes locais, realizando-se assim comparativos entre diferentes instituições. Estudos, estes, que visem capturar diferenças no comportamento dos consumidores cruzando variados fatores, visando identificar diferenças quanto a hábitos locais, culturais, sociais, econômicos e psicológicos.

\section{REFERÊNCIAS}

ASSAEL, Henry. Consumer bahavior and marketing action. Boston: PWS Kent, 1992;

Data Escola Brasil. Publicado em 2015 por INEP. Disponível em: <http://www.dataescolabrasil.inep.gov.br/dataEscolaBrasil/> Acesso em 02 abr. 2017.

CRESCER. Escola é melhor do que babá para o desenvolvimento infantil. Revista Crescer. Revista Produção on-line. Julho, 2017. Disponível em:

$<$ https://revistacrescer.globo.com/Criancas/Escola/noticia/2017/07/pesquisa-escola-e-melhordo-que-baba-para-o-desenvolvimento-

infantil.html?utm_source=facebook\&utm_medium $=$ social\&utm_campaign=post $>$ Acesso em 01 mai. 2018.

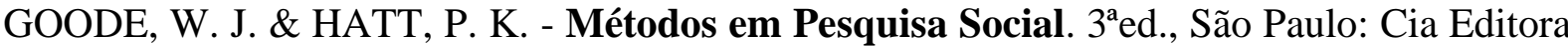
Nacional, 1969.

KARSAKLIAN, Eliane. Comportamento do Consumidor. - 1. Ed. São Paulo: Atlas, 2000.

GIL, A. C. Como elaborar projetos de pesquisa. São Paulo: Atlas, 2002.

GRINBERG, Paulo. Jung, o Homem Criativo. São Paulo: FTD, 1997.

HALL, Calvin S.; NORDBY, Vernon J. Introdução à Psicologia Junguiana. São Paulo: Cultrix, 2000.

HONG KONG AND SHANGHAI BANKING CORPORATION - HSBC. O Valor da Educação. Relatório do Brasil. Publicado em 2014 por HSBC Holdings plc. Disponível em: $\leq$ https://www.hsbc.com.br/1/PA_esf-ca-app-content/content/hbbr-pwsgip16/portugues/personal/comum/pdf/relatorio-global-pt.pdf $\geq$ Acesso em: 02 set. 2016.

KOTLER, Philip. Administração de Marketing: a edição do novo milênio; tradução Bazán Tecnologia e Linguística; revisão técnica Arão Sapiro. São Paulo: Prentice Hall, 2000.

KOTLER, Philip; KELLER, Kevin Lane. Administração de marketing. 12. ed. São Paulo: Pearson Prentice Hall, 2006.

LAS CASAS, Alexandre Luzzi. Administração de marketing: conceitos, planejamento e aplicações à realidade brasileira. 1. ed. São Paulo: Atlas, 2012. 
NOGUEIRA, M. A. A escolha do estabelecimento de ensino pelas famílias: a ação discreta da riqueza cultural. Revista Brasileira de Educação, Rio de Janeiro: ANPEd; Campinas: Autores Associados, n. 7, p. 42-56, jan./abr. 1998.

INSTITUTO BRASILEIRO DE GEOGRAFIA E ESTATÍSTICA - IBGE. Pesquisa Mensal de Emprego. Publicado em 2008 por IBGE. Disponível em: $<$ https://www.ibge.gov.br/home/estatistica/indicadores/trabalhoerendimento/pme_mulher/Sup lemento_Mulher_2008.pdf> Acesso em: 01 abr. 2017.

PETER, J. Paul. OLSON, Jerry C. Comportamento do Consumidor e estratégia de marketing; tradução: Beth Honorato; revisão técnica Cláudia Szafir-Goldstein, Mateus Tavares da Silva Cozer. - 8. ed. São Paulo: McGraw-Hill, 2009.

PRODANOV, Cleber Cristiano. FREITAS, Ernani Cesar de. Metodologia do trabalho científico: métodos e técnicas da pesquisa e do trabalho acadêmico - 2. ed. - Novo Hamburgo: Feevale, 2013.

RAPHEL, Murray. A escala da lealdade. Revista HSM. n. 13, mar./abr., p. 72-76, 1999.

SANTANA, Leonardo. Simbolismo do fogo e tentativas de suicídio. Brasília: UniCEUB, 2005. p. 20-21. Disponível em: <http://repositorio.uniceub.br/jspui/bitstream/123456789/3052/2/20059672.pdf> Acesso em 02 abr. 2017.

SIMÕES, Fatima Itsue Watanabe.; HASHIMOTO, Franscisco. Mulher, mercado de trabalho e as configurações familiares do século XX. Minas Gerais: UFVJM, 2012. 25 p., Revista Vozes dos Vales: Publicações Acadêmicas.

SOLOMON, Michael R. O Comportamento do Consumidor: Comprando, possuindo e Sendo; tradução: Beth Honorato. -11. Ed. - Porto Alegre: Bookman, 2016.

SHETH, Jagdish N.; MITTAL, Banwari; NEWMAN, Bruce I. Comportamento do cliente: indo além do comportamento do consumidor. São Paulo: Atlas, 2001. 